\title{
Interaction of creep with the martensitic transformation in TiPdNi High Temperature Shape Memory Alloys
}

\author{
Dimitris C. Lagoudas ${ }^{1, a}$ and Parikshith K. Kumar ${ }^{2}$ \\ 1 Dept. of Aerospace Engineering, Texas A\&M University, College Station, TX 77843, USA \\ 2 Dept. of Materials Science \& Engineering, Texas A\&M University, College Station, TX 77843, USA
}

\begin{abstract}
High Temperature Shape Memory Alloys represent a class of Shape Memory Alloys with transformation temperatures greater than $100^{\circ} \mathrm{C}$. However, as a consequence of their high transformation temperatures, these alloys can be exposed to a temperature regime where creep behavior can occur simultaneously during the phase transformation. Depending on the transformation temperatures of a shape memory alloy, the rate dependent plastic strain generated at the high operating temperatures, can significantly impact the actuators performance. The present effort focuses on understanding the interaction between the phase transformation and creep occurring simultaneously in shape memory alloys. For this purpose two alloys with transformation temperatures that overlap with the creep regime of the material are selected and fabricated by hot rolling/extrusion. Compression specimens are machined from the rolled material and standard isothermal creep tests are conducted at specific stress levels. In addition transformation induced thermal cycling is conducted to study the simultaneous transformation/viscoplastic behavior. Optical microscopy and TEM studies are conducted on the tested specimen to observe the changes in the microstructure. Based on the thermomechanical tests and the microstructural observations suitable conclusions are drawn to explain the interaction between the two mechanisms.
\end{abstract}

\section{Introduction}

Over the last decade, the interest in actuators capable of operating in high temperature environments has increased the focus towards High Temperature Shape Memory Alloys (HTSMAs) with transformation temperatures that exceed $100^{\circ} \mathrm{C}[1,2]$. Most recent studies on HTSMAs have focussed on studying and improving the actuation characteristics and processing methods for the alloy [3-5]. Newer alloys with higher transformation temperatures are constantly being developed [6-10]. With the increase in the transformation temperatures, the phase transformation can overlap with the temperature regime where creep is observed causing the two mechanisms to occur simultaneously.

Creep tests have been conducted on conventional NiTi alloys in the austenitic state to gain a better understanding of the forming processes. These tests have been conducted at temperatures ranging from approximately $500^{\circ} \mathrm{C}-1100^{\circ} \mathrm{C}$ [11-14], temperatures which are significantly higher that the region where phase transformation occurs and as a consequence the interaction between creep and transformation was never observed. In the case of HTSMAs these phenomena can simultaneously occur, however the interaction between the two phenomenon has not been addressed in the past work. The present effort focusses on studying the simultaneous creep and

\footnotetext{
a e-mail: lagoudas@aero.tamu.edu
}

This is an Open Access article distributed under the terms of the Creative Commons Attribution-Noncommercial License (http://creativecommons.org/licenses/by-nc/3.0/), which permits unrestricted use, distribution, and reproduction in any noncommercial medium, provided the original work is properly cited. 
transformation phenomena and understanding the underlying microstructural changes due to this process. For this purpose $T i_{50} P d_{30} N i_{20}$ and $T i_{50} P d_{40} N i_{10}$ HTSMAs are selected because their transformation temperatures lie within $0.3-0.5$ of their absolute melting temperature, the range within which creep behavior initiates in metallic systems. Following preliminary tests to study the creep behavior of these alloys, isobaric thermal cycling tests at a predetermined heating/cooling rate are conducted to study the simultaneous interaction between the phase transformation and viscoplastic behavior. Following the test, studies of the microstructure are conducted on thin sections of the test specimen.

\section{Experimental method}

An ingot of the $T i_{50} P d_{40} N i_{10}$ HTSMA was fabricated by vacuum arc melting and the cast bar was hot rolled at $900^{\circ} \mathrm{C}$, with intermediate heating in a inert gas purged furnace to avoid excessive oxidation. The thickness of the bar was reduced by $30 \%$ during the rolling process. 12 mm length x $6 \mathrm{~mm}$ diameter compression specimen were cut from the hot rolled bar along the rolling direction. A second set of compression specimens from a hot extruded $T i_{50} P d_{30} N i_{20}$ HTSMA bar were obtained from NASA Glenn Research Center. The thermomechanical tests on the specimen were conducted using an MTS frame equipped with Inconel compression grips and a water cooled quad lamp furnace. The load cell measuring the force was separated from the furnace by a water cooled jacket and the specimen strain was measured using a water cooled extensometer. The extensometer was mounted on the specimen grips and the thermal expansion due to the grips was subtracted to obtain the strain due to the HTSMA. The furnace lamp intensities were adjusted based on the feedback received from the thermocouple mounted on the specimen surface. The strain, force, temperature and time were recorded by the MTS software.

Creep tests were conducted on the compression specimens at stress levels ranging of 100 to $500 \mathrm{MPa}$ at temperatures ranging from $300-500^{\circ} \mathrm{C}$ (austenitic state). In each case the specimen was isothermally loaded to the desired stress level and the stress was held constant until a steady state creep behavior was observed and the strain evolution with time is recorded. A new specimen was used for the creep test at each stress level.

To study the simultaneous viscoplastic and transformation behavior, isobaric thermal cycling tests were conducted at chosen stress levels and at chosen heating/cooling ranging based on the creep behavior observed. For each isothermal cycling case the specimen was held at the test temperature and subsequently loaded under isothermally loading conditions to a constant stress level. The stress was held constant and the specimen was then thermally cycled through a complete phase transformation at the chosen heating/cooling rate. The same loading path was repeated for different stress levels and/or at different heating/cooling rates.

Following the thermomechanical tests, thin sections of the test specimens were polished to a 1 micron surface finish for observation under an optical microscope. Additionally thin foils were prepared for observation in a TEM equipped with a heating stage. Thin sections were machined using a diamond saw from the test specimens and polished down to a 3 micron surface finish. The specimens were subsequently dimpled using a 9 micron diamond slurry and polished using an ion mill untill a small hole was formed at the center. The specimen's microstructure was examined using a JOEL 2010 TEM.

\section{Results and Discussion}

The results from preliminary isobaric thermal cycling tests at two different heating/cooling rates of $2^{\circ} \mathrm{C} / \mathrm{min}$ and $20^{\circ} \mathrm{C} / \mathrm{min}$ under a constant stress of $200 \mathrm{MPa}$ on a $T i_{50} P d_{40} N i_{10} \mathrm{HTSMA}$ are shown in Fig. 1. In Fig. 1, the specimen is initially loaded to a stress of $200 \mathrm{MPa}$ at $520^{\circ} \mathrm{C}$. The specimen is then cooled through the transformation region to a temperature of $300^{\circ} \mathrm{C}$ and subsequently heated back to $520^{\circ} \mathrm{C}$ through the reverse transformation. From the results it is observed that the HTSMA begins to creep in the initial austenitic phase upon 


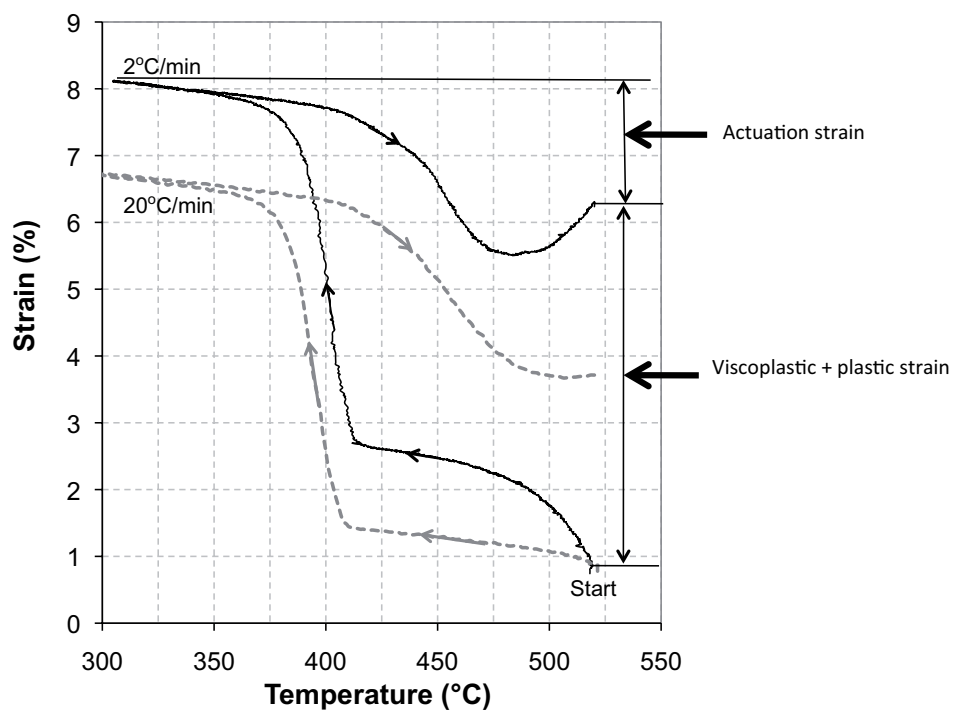

Fig. 1. Please write your figure caption here.

cooling during the forward transformation (visible in the both the $2^{\circ} \mathrm{C} / \mathrm{min}$ and the $20^{\circ} \mathrm{C} / \mathrm{min}$ cases). The amount of creep strain is lower in the $20^{\circ} \mathrm{C} / \mathrm{min}$ case due to the lower time of exposure at each temperature for the generation of creep strain. The creep strain rate constantly decreases as the temperature is lowered and towards the end of the forward transformation no significant influence of the generated creep strain is observed. Upon the initiation of the reverse transformation the materials begins to transform from martensite to austenite. However with the increase in temperature the creep rate also begins to increase and at a temperature of $480^{\circ} \mathrm{C}$, it is noticed that the rate at which creep strain generated exceeds the rate at which the phase transformation occurs (controlled by the rate of heating), thereby causing a decrease in the actuation strain (i.e. strain generated upon the heating cycle) at the expense of the viscoplastic strain generated. This effect is also observed in the $20^{\circ} \mathrm{C} / \mathrm{min}$ case but the impact of the viscoplastic behavior is lower due to the higher heating/cooling rate.

Preliminary TEM studies conducted on the $20^{\circ} \mathrm{C} / \mathrm{min}$ thermally cycled specimen, indicate the presence of retained martensite even after heating the specimen to a temperature of $520^{\circ} \mathrm{C}$. The micrograph from the TEM study is shown in Fig. 2, indicating region B that has completely transformed to austenite and region A this still shows the presence of retained martensite. The thermomechanical tests and microstructural studies are conducted for the $T i_{50} P d_{30} N i_{20}$ HTSMA and are compared with the results observed for the $T i_{50} P d_{40} N i_{10}$ HTSMA.

\section{References}

1. Otsuka, K. and Wayman, C. M. (Eds.) 1999. "Shape Memory Materials," Cambridge University Press, Cambridge.

2. Lagoudas, D. C. (Ed.) 2007. "Shape Memory Alloys: Modeling and Engineering Applications," Springer.

3. Kumar, P. K., Lagoudas, D. C., Zanca, K. J. and Lagoudas, M. Z.2006. "Thermomechanical characterization of high temperature sma actuators," Proceedings of SPIE, 6170:306-312.

4. Noebe, R., Draper, S., Gaydosh, D., Garg, A., Lerch, B., Bigelow, G. and Padula II, S. 2006. "Effect of thermomechanical processing on the microstucture, properties, and work behavior of a $T i_{50.5} N i_{49.5} P t_{20}$ high-temperature shape memory alloy," Proceedings of the International Conference on Shape Memory and Superelastic Technologies, ASM International, Metals Park, OH.

5. Padula II, S., Bigelow, G., Noebe, R., Gaydosh, D. and Garg, A. 2006. "Challenges and progress in the development of high-temperature shape memory alloys based on NiTiX compositions for 


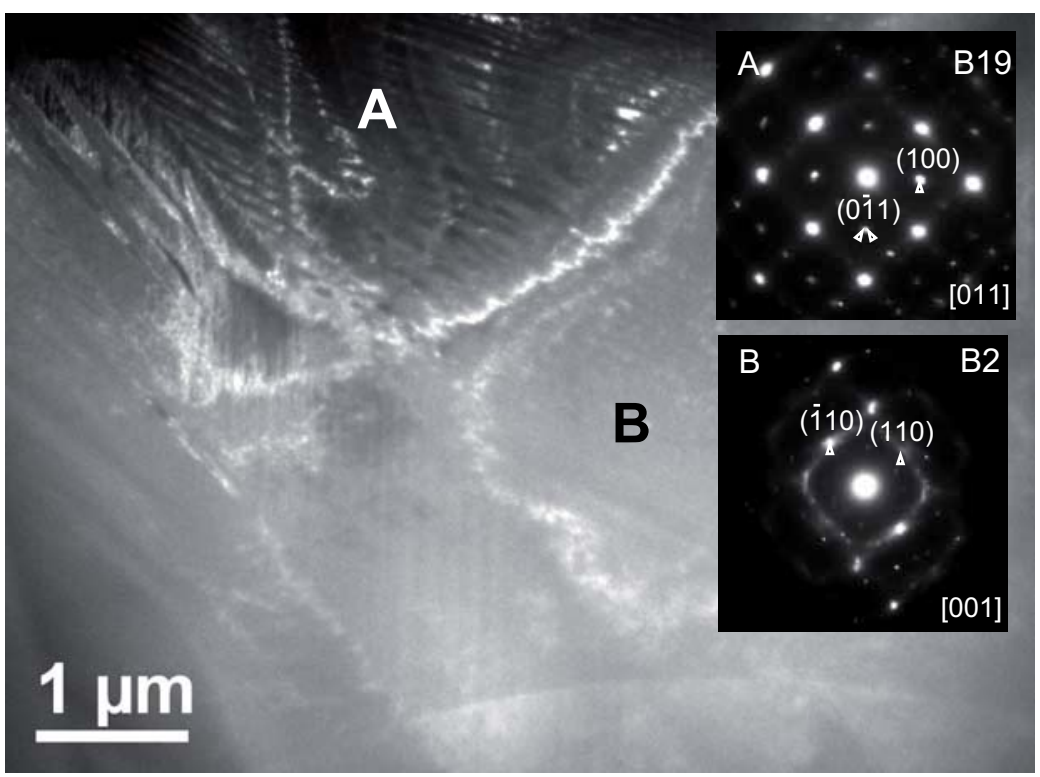

Fig. 2. TEM micrograph of the $20^{\circ} \mathrm{C} / \mathrm{min}$ thermally cycled specimen at a temperature of $520^{\circ} \mathrm{C}$. The region $\mathrm{A}$ in the microstructure shows martensite that has not transformed which is embedded in the matrix which is austenite (indicated by region B).

high-force actuator applications," Proceedings of the International Conference on Shape Memory and Superelastic Technologies, ASM International, Metals Park, OH.

6. Doonkersloot, H. C. and Vucht, V. 1970. "Martensitic transformations in Au-Ti, Pd-Ti and Pt-Ti alloys," Journal of Less Common Metals, 20:83-91.

7. Lidquist, P. and Wayman C. M. 1990. "Shape memory and transformation behavior of martensitic Ti-Pd-Ni and Ti-Pt-Ni alloys, Engineering Aspects of Shape Memory Alloys," ButterworthHeinemann, London.

8. Pu, Z., Tseng, H. and Wu, K. 1995. "Martensite transformation and shape-memory effect of NiTi-Zr high- temperature shape-memory alloys," Proceedings of SPIE, Vol. 2441. p. 171

9. Thoma, P. E. and Boehm, J. J. 1999. "Effect of composition on the amount of second phase and transformation temperatures of $N i_{x} T i_{90-x} H f_{10}$ shape memory alloys," Materials Science and Engineering A, 273-275:385-389.

10. Biggs, T., Cortie, M. B., Witcomb, M. J. and Cornish, L. A. 2003. "Platinum alloys for shape memory applications," Platinum Metals Rev, 47(4):142-146.

11. Mukherjee, A. K. 1968. "High-temperature-creep mechanism of TiNi," Journal of Applied Physics, 39(5):2201-611.

12. Eggeler, G., Khalil-Allafi, J., Neuking, K. and Dlouhy, A. 2002. "Creep of binary Ni-rich NiTi shape memory alloys and the influence of pre-creep on martensitic transformations," Zeitschrift für Metallkunde, 93:654-660.

13. Lexcellent, C., Robinet, P., Bernardini, J., Beke, D. L. and Olier, P. 2005. "High temperature creep measurements in equiatomic Ni-Ti shape memory alloy," Materialwissenschaft und Werkstofftechnik, 36(10):509-512.

14. Oppenheimer, S. M., Yung, A. R. and Dunand, D. C. 2007. "Power-law creep in near-equiatomic nickel-titanium alloys," Scripta Materialia, 57:377-380. 